\title{
Acrometástasis óseas, serie de casos y revisión de la literatura
}

Pablo Arbeláez Echeverri ${ }^{*}$, María Fernanda García ${ }^{2}$, Julián Garzón $C^{3}$, Laura Cristina Morales ${ }^{4}$, Oscar Messa Botero $^{5}$, María Isabel Zúñiga ${ }^{6}$, Cesar José Lozada Mujica ${ }^{7}$.

1. Médico ortopedista. Hospital Universitario San Ignacio. Bogotá D.C, Colombia.

2. Residente primer año ortopedia. Hospital Universitario San Ignacio. Bogotá D.C, Colombia.

3. Médico radiólogo. Hospital Universitario San Ignacio. Bogotá D.C, Colombia.

4. Residente primer año radiología. Hospital Universitario San Ignacio. Bogotá D.C, Colombia.

5. Médico patólogo oncólogo. Hospital Universitario San Ignacio. Bogotá D.C, Colombia.

6. Residente primer año patología. Hospital Universitario San Ignacio. Bogotá D.C, Colombia.

7. Médico general. Hospital Universitario San Ignacio. Bogotá D.C, Colombia.

\section{Bone acrometástasis, case series and literature review}

Resumen: Las acrometástasis se definen como metástasis óseas localizadas distales al codo y la rodilla. Su prevalencia es muy baja, aproximadamente el 0,1\% de todas las metástasis óseas y se presentan en pacientes con enfermedad avanzada y son indicador de mal pronóstico. Hasta en el $10 \%$ de los casos se presentan como el primer signo de neoplasia oculta. Su forma de presentación clínica y radiológica es inespecífica, lo que genera retraso en su diagnóstico y tratamiento. La resonancia magnética es la imagen de elección para el diagnóstico. El tratamiento en la mayoría de los casos es paliativo. Presentamos cuatro pacientes con acrometástasis y una revisión de la literatura.

Palabras clave: Acrometástasis, Neoplasias, Oseas.

Abtract: Acrometastasis are defined as localized bone metastases distal to the elbow and knee. Its prevalence is very low, approximately $0.1 \%$ of all bone metastases and they present in patients with advanced disease and are considered indicators of poor prognosis. In up to $10 \%$ of cases are the first sign of undiagnosed neoplasia. Its clinical and radiological presentation is non-specific which generates delays in its diagnosis and treatment. Magnetic resonance is the image of choice for diagnosis. The treatment in most cases is palliative. We present four patients with acrometastasis and a review of the literature.

Keywords: Acrometástasis, Bones, Neoplasms.

Arbeláez P, et al. Acrometástasis óseas, serie de casos y revisión de la literatura. Rev Chil Radiol 2019; 25(3): 87-93. *Correo electrónico: Pablo Arbeláez Echeverri / parbelaezechev@hotmail.com.

Trabajo enviado el 29 de julio de 2019. Aceptado para publicación el 03 de agosto de 2019.

\section{Introducción}

Las acrometástasis se definen como metástasis óseas localizadas distales al codo y la rodilla ${ }^{(1)}$. Su prevalencia es muy baja, representando aproximadamente el $0,1 \%$ de todas las metástasis óseas ${ }^{(1,2,4)}$. Usualmente se presentan en pacientes con enfermedad avanzada y se consideran indicadores de mal pronóstico ${ }^{(1)}$. Las neoplasias primarias generalmente se originan en pulmón, glándula mamaria, tracto gastrointestinal y genitourinario ${ }^{(1,3)}$. Por lo general se diagnostican en pacientes que tienen una neoplasia bien documentada, sin embargo, hasta en el $10 \%$ de los casos se presentan como el primer signo de neoplasia oculta ${ }^{(1,3,4)}$. Su forma de presentación clínica es inespecífica y simula otras enfermedades, lo que genera retraso en su diagnóstico y tratamiento ${ }^{(2,5)}$. La baja prevalencia y el aspecto inespecífico en la radiografía convencional dificulta el diagnóstico temprano. La resonancia magnética (RM) es la imagen de elección para el diagnóstic ${ }^{(1,6)}$. El tratamiento en la mayoría de los casos es paliativo, centrado en el control del dolor y la sintomatología local con radioterapia y cirugía; y la prevención de nuevas metástasis.

Presentamos cuatro pacientes con diagnóstico histopatológico de acrometástasis, recolectados en el año 2018 en el Hospital Universitario San Ignacio, Bogotá D.C., y una revisión de la literatura de esta localización secundaria poco frecuente. 


\section{Descripción de los casos}

Caso 1

Hombre de 57 años con antecedente de adenocarcinoma gástrico manejado con gastrectomía total, vaciamiento ganglionar y quimioterapia adyuvante. Once meses después de la cirugía, se documentó carcinoma escamocelular ulcerado en el tercio medio del esófago. En estudios de extensión, se describió infiltración neoplásica a tráquea, adenopatías cervicales, mediastínicas, inguinales y retroperitoneales.

Consultó 4 meses después por calor y rubor en la articulación interfalángica del pulgar izquierdo. La radiografía (Figuras 1 y 2) evidenció una lesión lítica localizada en la falange distal del primer dedo izquierdo. Inicialmente entre los diagnósticos diferenciales se consideró osteomielitis, metástasis, condrosarcoma y tumor de células gigantes.

Se tomó biopsia abierta con cultivos de lesión en falange distal, descartando compromiso infeccioso. La patología evidenció compromiso por carcinoma escamocelular de célula grande metastásico de primario esofágico conocido (Figura 3). Con este diagnóstico, se inició tratamiento paliativo sistémico y radioterapia.

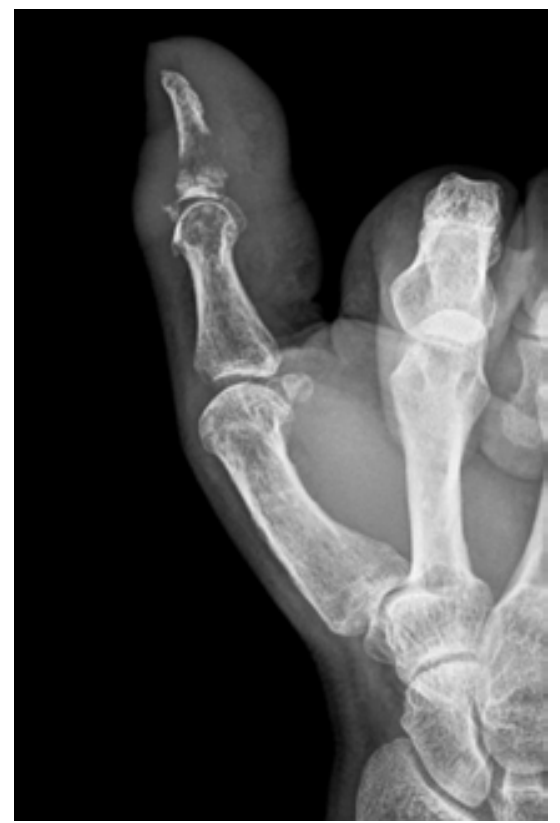

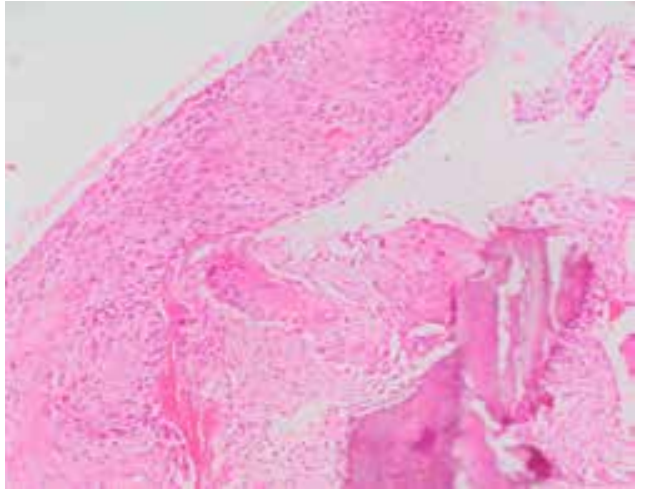

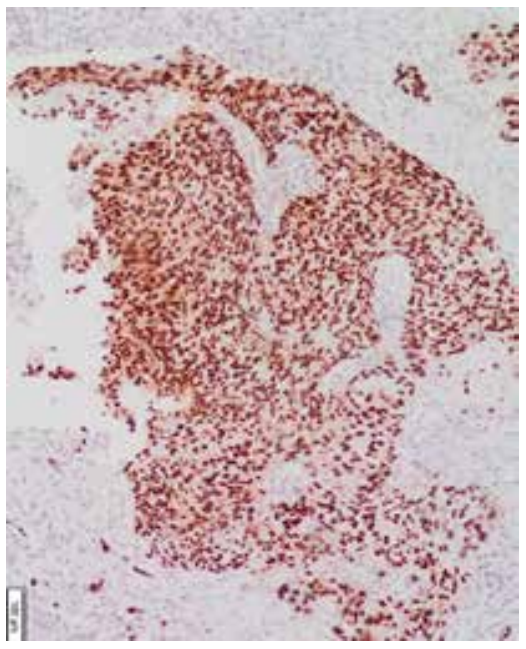

Figura 3. Carcinoma escamocelular metastásico (H/E, 10 x); queratinización y disqueratocitos individuales (a). Estudio de inmunohistoquímica positivo para Citoqueratina 34BE12 y 5/6 y $P 63$ (b), con negatividad para CK7, CK20, y TTF1.

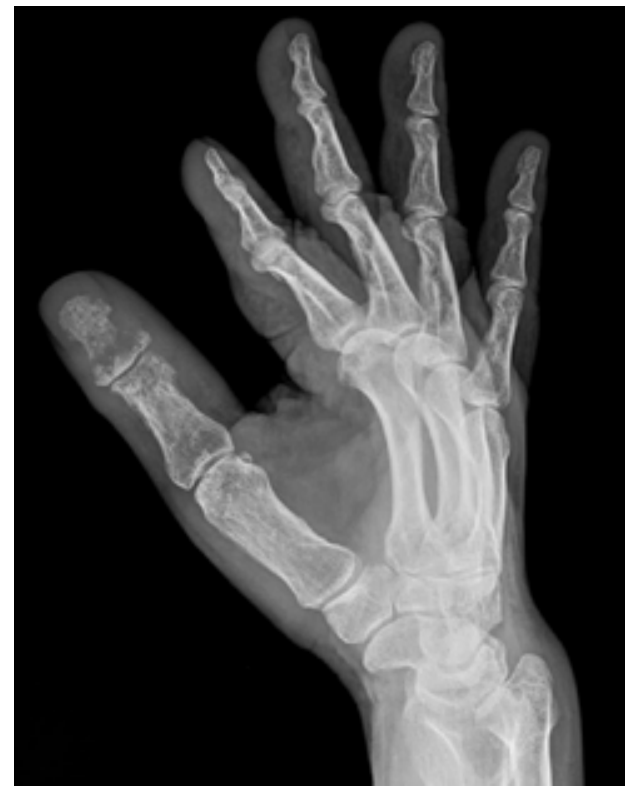

Figura 1 y 2. Radiografía lateral de dedo y mano izquierda. Lesión lítica localizada en la falange distal del primer dedo, que compromete la cortical anterior y posterior, de márgenes irregulares, con zona de transición amplia, sin matriz calcificada y sin reacción perióstica. Adicionalmente, se observa masa de tejidos blandos que se extiende hacia el pulpejo, con extenso edema de tejidos blandos. 


\section{Caso 2}

Hombre de 83 años con diagnóstico de carcinoma de próstata quien recibió manejo con terapia hormonal. En el seguimiento se documentó elevación de los niveles de PSA, al examen físico presentaba edema, limitación para el apoyo y dolor persistente en tobillo derecho, sin lesiones cutáneas asociadas. La radiografía (Figuras 4 y 5) identificó una lesión ósea blástica.

Se realizó orquiectomía y biopsia abierta de la tibia distal. En la patología se evidenció hueso comprometido por adenocarcinoma metastásico prostático (Figura 6a y 6b). Con este resultado, se inició tratamiento con radioterapia y antirresortivos.

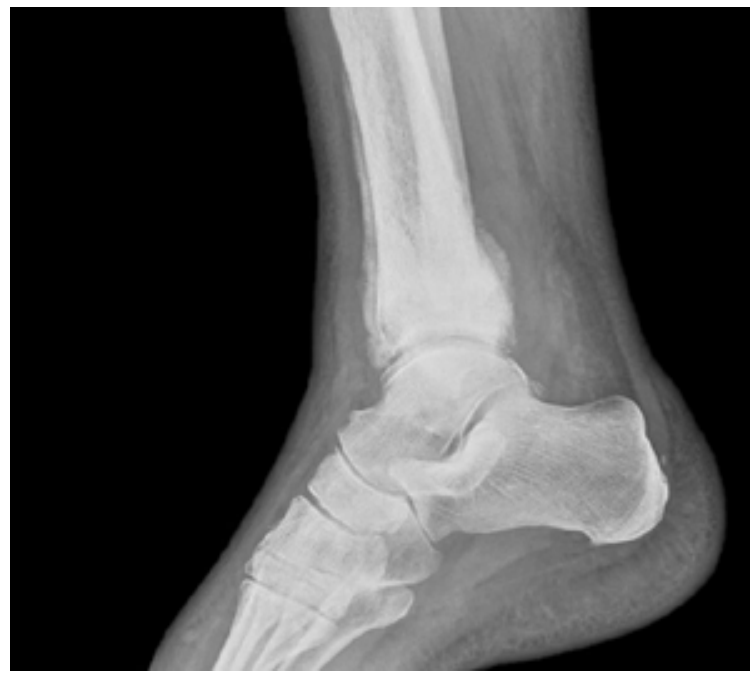

Caso 3

Mujer de 49 años con antecedente de exposición a corticoides durante 4 años como parte de un tratamiento dermatológico del cual se desconoce el diagnóstico. Consultó por gonalgia izquierda de 2 años de evolución sin trauma asociado, sin hallazgos positivos al examen físico.

Se realizó un cintigrama óseo (Figura 7) y tomografía computarizada (TC) (Figura 8) con lo que se consideró inicialmente diagnóstico de osteonecrosis por exposición a corticoides. Se tomó biopsia percutánea de la metáfisis de la tibial proximal y femoral distal, en la que se identificó hueso y tejidos blandos comprometidos por un adenocarcinoma metastásico de primario gastrointestinal alto desconocido (Figura 9).

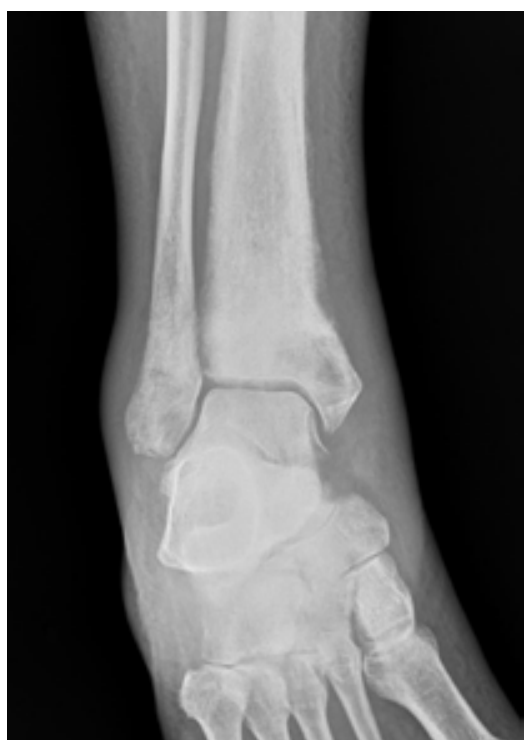

Figura 4 y 5. Radiografía AP y lateral de tobillo derecho. Lesión blástica de márgenes mal definidos, zona de transición amplia, localizada en la metáfisis y epífisis distal de la tibia, con abombamiento de las corticales anterior y posterior, y masa extraósea por permeación cortical.
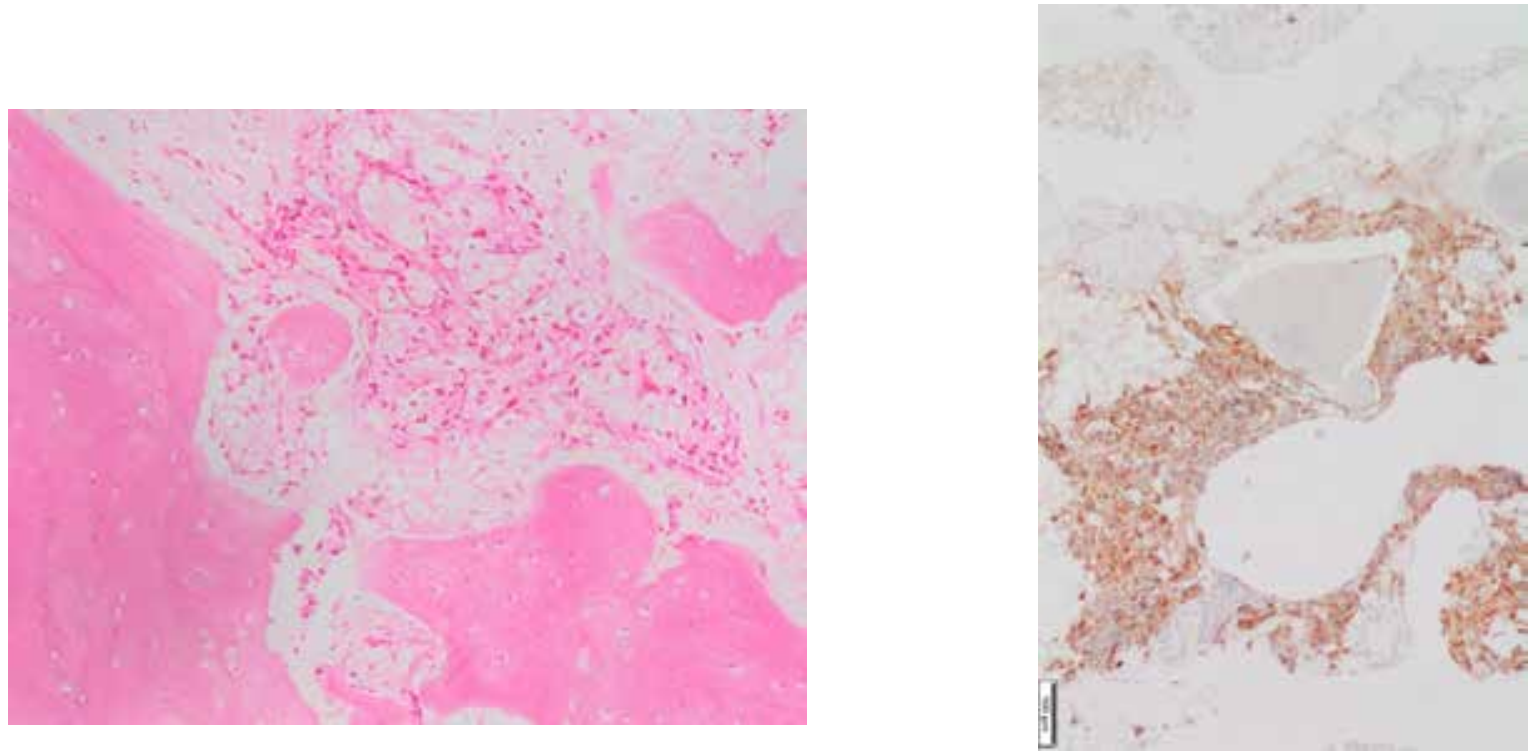

Figura 6. Hueso comprometido por adenocarcinoma con formación focal de luces (H/E 40x) (a). El estudio de inmunohistoquímica fue positivo para CK (AE1AE3) y PSA (b) y negativo para CK7, CK20, P.63, TTF1, CDX2 y sinaptofisina. 


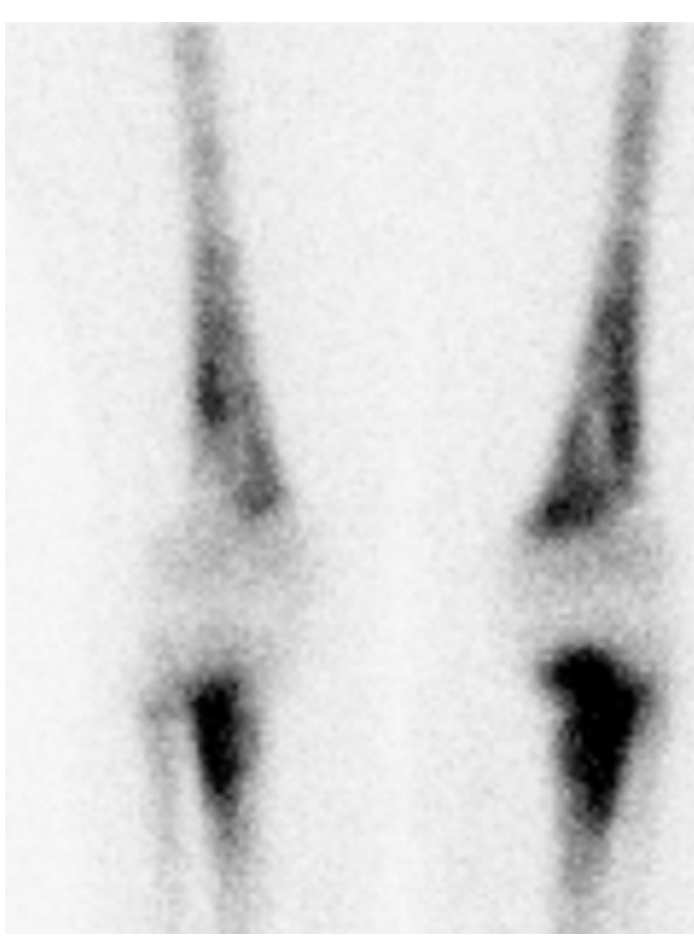

Figura 7. Gammagrafía ósea. Se identifica incremento difuso en la captación del trazador, tanto en esqueleto axial como apendicular, especialmente en humeros, fémures y aspectos proximales de la tibia.

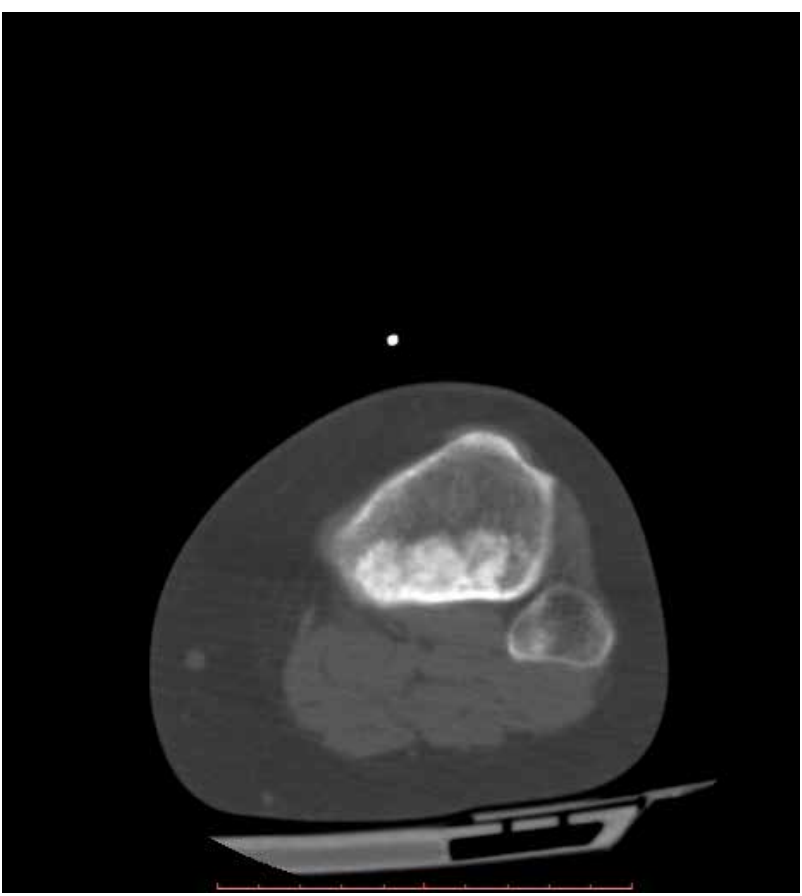

Figura 8. Tomografía computarizada de pierna izquierda, corte axial. Lesión excéntrica, posterior en la diáfisis tibial con matriz calcificada de márgenes circunscritos y zona de transición estrecha, sin reacción perióstica ni masa de tejidos blandos.
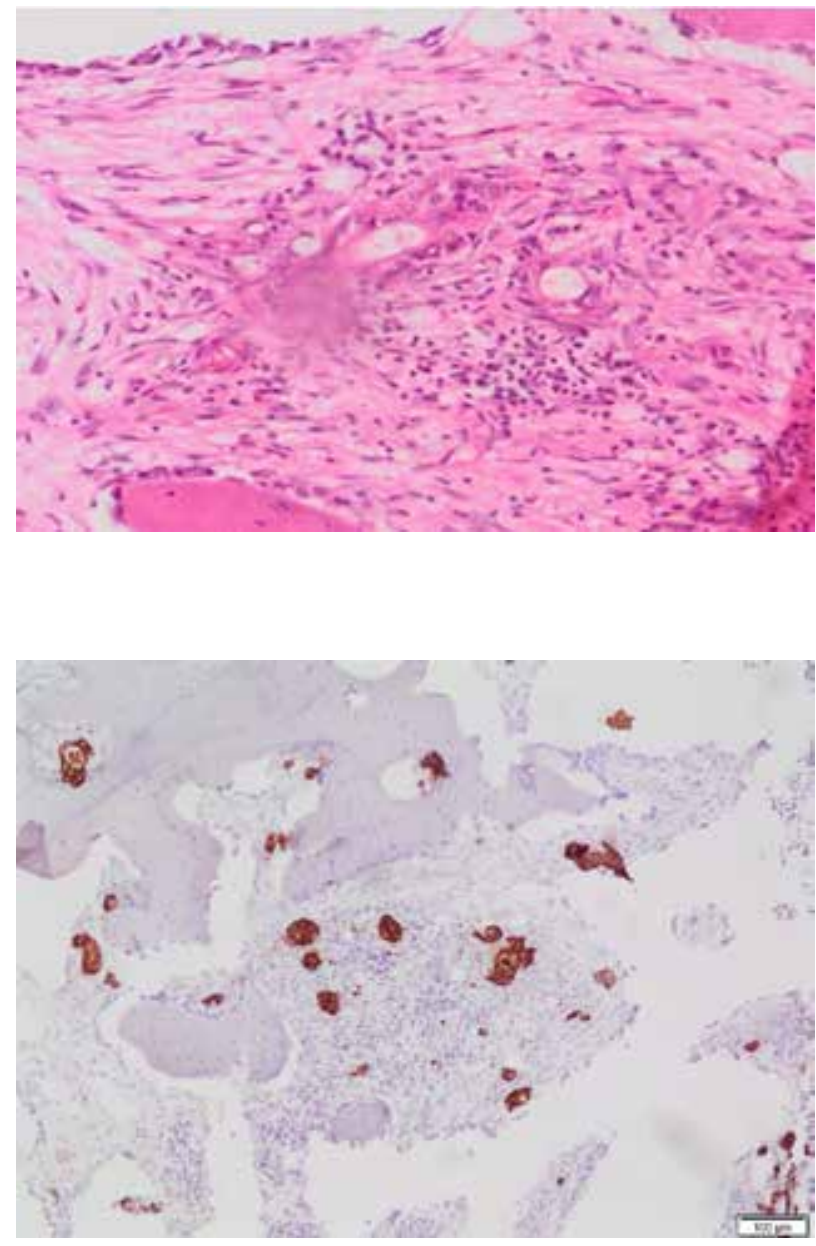

Figura 9a-b. Hueso con adenocarcinoma metastásico con formación de luces (H/E 10X) (a). Estudio de inmunohistoquímica positivo difuso para CK (AE1AE3) CK7 (b); y muy focal para CK20, CDX2 y CA125. No hubo reactividad para TTF1, GATA3, PAX8, receptor de estrógenos ni WT1.

\section{Caso 4}

Mujer de 76 años con carcinoma urotelial papilar de vejiga localmente avanzado, quien consultó por dolor lumbar, en caderas y talón izquierdo. En el cintigrama óseo (CO) se identificó compromiso poliostótico metastásico (Figura 10).

Se realizó biopsia abierta de calcáneo izquierdo, obteniendo un tejido pardo, violáceo de consistencia blanda. En el estudio histopatológico se observó hueso comprometido por un carcinoma metastásico de origen vesical (Figura 11). Con estos resultados se inició quimioterapia con intención paliativa y antirresortivo. 
Figura 10. Gammagrafía ósea. Compromiso poliostótico metastásico en columna dorsal, sacro y hemipelvis izquierda, con focos hipercaptantes en el calcáneo izquierdo
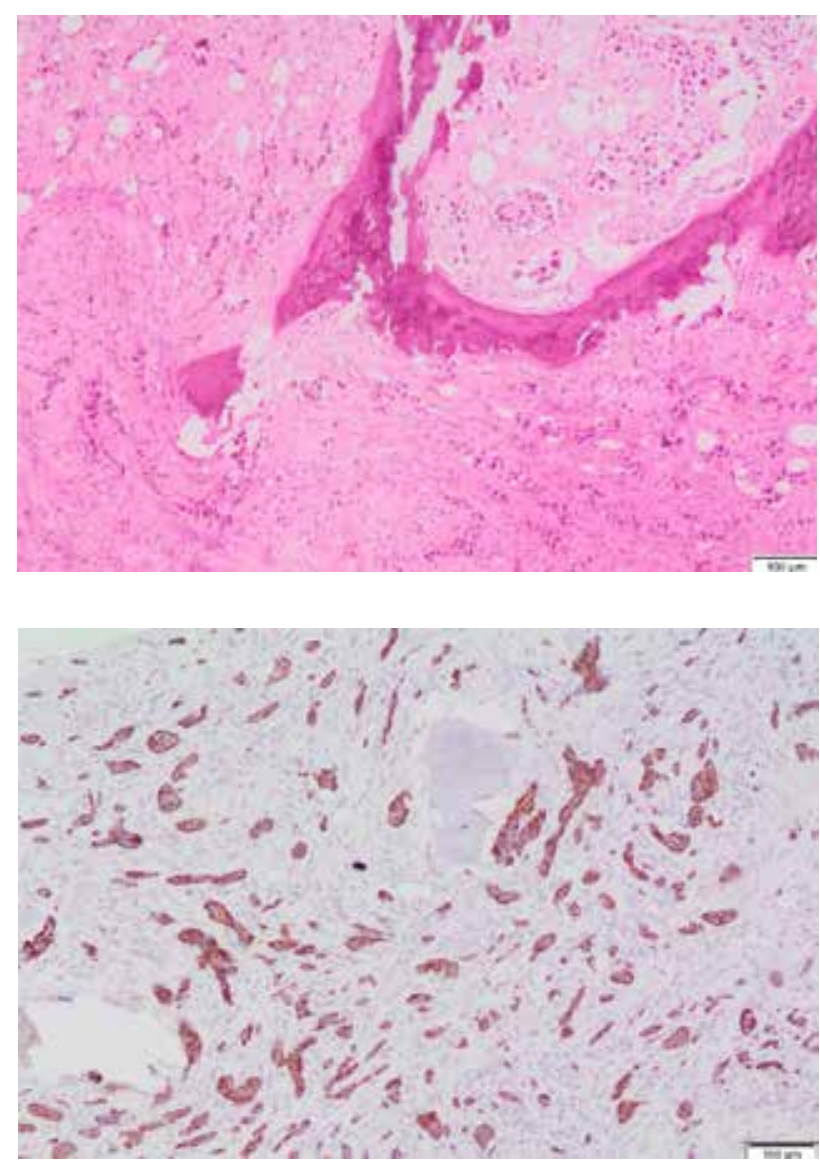

Figura 11. Huesos con nidos pequeños. Carcinoma metastásico (H/E 10X) a. Estudio de inmunoistoquímica positivo para CK (AE1 AE3). b. CK7, CK20, uroplaquina y GATA3 focal; con negatividad para TTF1, CDX2, receptores de estrógenos y progestógenos.

\section{Discusión}

Las metástasis óseas son comunes en la historia natural de los pacientes con cáncer, siendo el tercer órgano más frecuentemente afectado después del pulmón e hígado ${ }^{(1,6)}$. Son lesiones más prevalentes que las óseas primarias ${ }^{(6)}$. Las acrometástasis se definen como metástasis óseas localizadas distales a los codos y rodillas ${ }^{(1)}$. Su prevalencia es baja, representando el $0.1 \%$ de todas las metástasis óseas ${ }^{(1,7)}$. Se presentan con mayor frecuencia en hombres y su hallazgo se considera factor de mal pronóstico. Por lo general, se presentan en pacientes que cursan con enfermedad avanzada; sin embargo, hasta en $10 \%$ de los casos, representan el primer signo de neoplasia oculta ${ }^{(1,3)}$.

Existen algunos órganos más propensos a generar metástasis en el tejido óseo y se denominan osteotrópicos ${ }^{(6)}$. El cáncer de pulmón es la neoplasia primaria maligna en al menos el $50 \%$ de las metástasis acrales, seguido por el carcinoma de células renales, colorrectal y mama ${ }^{(1,6)}$. Se cree que la alta incidencia de acrometástasis secundarias a cáncer pulmonar, se debe a que las células neoplásicas embolizan a todos los órganos, sin un lecho capilar que haga las veces de filtro antes de llegar a su destino.

Los sitios anatómicos más frecuentemente afectados por acrometástasis son falanges, hueso escafoides y semilunar ${ }^{(6)}$. De acuerdo con lo reportado por Flynn et al(8), el dedo medio es el más frecuentemente comprometido ${ }^{(8)}$. La falange distal es la región más afectada, seguida por metacarpos, falanges proximales y medias. En el pie, se comprometen con más frecuencia el astrágalo y calcáneo ${ }^{(1,2)}$.

De acuerdo, con la revisión realizada por Stomeo et al. ${ }^{(1)}$, algunos tumores muestran predilección por la mano y otros por el pie. Este fenómeno se debe a que los tumores supra diafragmáticos alcanzan la circulación arterial sistémica y, por ende, las mano. Por el contrario, las neoplasias infra diafragmáticas usualmente metastatizan al pie de forma retrograda a través del plexo venoso vertebral de Batson ${ }^{(1,9)}$.

En cuanto a la fisiopatología, las metástasis óseas se producen por extensión directa o, más frecuentemente, por diseminación arterial o venosa ${ }^{(6,12)}$. Las metástasis requieren de un proceso que inicia con la liberación de las células neoplásicas del lecho nativo, evasión del sistema inmunológico e invasión vascu$\operatorname{lar}^{\left({ }^{12}\right)}$. Una vez depositadas en los capilares óseos, se extravasan hacia la médula ósea para generar un tumor secundario ${ }^{(10,11)}$. Una vez colonizado el tejido óseo, las células neoplásicas interrumpen el proceso de remodelado normal del hueso, se genera destrucción ósea y liberación de ciertas citoquinas y factores de crecimiento que pueden estimular la actividad osteolítica u osteoblástica ${ }^{(6)}$. De esta forma las metástasis óseas pueden ser osteoblásticas u osteoliticas, aunque en la mayoría de los casos existe una combinación de las $\operatorname{dos}^{(6)}$. Por lo general, las metástasis de riñón, 
tiroides y pulmón son predominantemente osteoliticas; las de próstata blásticas, y las de mama y esófago mixtas $^{(1)}$. Entre otras teorías fisiopatológicas, algunos autores consideran que puede existir asociación con el antecedente de trauma, debido a la hiperemia que acompaña al proceso inflamatorio(8).

Las manifestaciones clínicas son: masa palpable, edema e inflamación de los tejidos blandos, eritema, ulceración, limitación funcional del segmento afectado y dolor intermitente y refractario al manejo medico(1). Los diagnósticos diferenciales incluyen: lesiones inflamatorias, gota, pseudogota, osteoartrosis, tenosinovitis, artritis reumatoidea, adenopatías, osteomielitis, dactilitis tuberculosa, granuloma piógeno y tumores primarios $^{(1,5)}$.

En cuanto a la evaluación radiológica de las acrometástasis existen técnicas de imagen morfológicas, como la radiografía convencional (RX), TC y RM que evalúan la estructura de la lesión, y otras técnicas cuantitativas que evalúan la función del tejido óseo y/o de las células tumorales, como el $\mathrm{CO}$ o técnicas hibridas como la tomografía por emisión de positrones (PET/CT) ${ }^{(6)}$.

La RX es el estudio inicial en casos de dolor óseo, sin embargo presenta una baja sensibilidad $(\mathrm{S} \%)$ para las metástasis asintomáticas)(6). Estudios han demostrado que debe existir una destrucción del tejido óseo de al menos $50-70 \%$ para que se observen cambios en la radiografía inicial) ${ }^{(6)}$. Las lesiones pueden ser blásticas o líticas dependiendo del tumor de origen ${ }^{(1)}$. Las lesiones osteolíticas presentan típicamente adelgazamiento trabecular y márgenes mal definidos) ${ }^{(6)}$. Por el contrario, las lesiones blásticas muestran engrosamiento trabecular y se manifiestan como lesiones bien circunscritas nodulares o redondeadas) ${ }^{(6)}$. En cuanto al seguimiento, la radiografía presenta ciertas limitaciones como la ausencia de cambios antes de los 3-6 meses de tratamiento, limitación en la valoración de tejidos blandos y baja capacidad para diferenciar entre esclerosis secundaria a progresión de la enfermedad y generada por un proceso de curación.

La sensibilidad y especificidad de la TC es de $74 \%$ y $56 \%$, respectivamente) ${ }^{(6)}$. La presencia de reconstrucciones multiplanares y excelente resolución espacial le representa una ventaja diagnóstica sobre la RX. Permite identificar lesiones metastásicas antes que se produzca la destrucción ósea característica, lo que resulta en un diagnóstico más temprano, mejoría en el pronóstico del paciente y prevención de complicaciones. Otra de sus ventajas es que puede emplearse como guía para biopsia percutánea.

La RM es el patrón de oro para valorar acrometástasis y el grado de compromiso extraóseo(1). Tiene una sensibilidad y especificidad de $95 \%$ y $90 \%$, respectivamente) ${ }^{(6)}$. Típicamente se identifican como focos pequeños hipointensos en secuencias poten- ciadas en T1 (por reemplazo de la medula grasa), hiperintensos en secuencias T2 y con realce tras la administración del medio de contraste) $)^{(6)}$.

La GM ósea tiene una sensibilidad y especificidad del $78 \%$ y $48 \%$, respectivamente) $)^{(6)}$. Lesiones escleróticas metastásicas pueden detectarse hasta 18 meses antes que en $R X)^{(6)}$. Los hallazgos dependen del flujo sanguíneo local, la actividad osteoblástica y extracción del radiotrazador) ${ }^{(6)}$. El principal problema es que múltiples lesiones benignas pueden presentar captación del radiotrazador, configurando falsos positivos)(6). Otras desventajas incluyen la pobre resolución espacial y que las lesiones osteoliticas con poca o ninguna reacción blástica pueden no acumular el radiotrazador, lo que correspondería con un falso negativo) ${ }^{(6)}$.

Finalmente, en la PET/TC las lesiones blásticas tienden a ser hipometabólicas y, por el contrario, las lesiones líticas hipermetabólicas. Es importante tener en cuenta que los protocolos usuales de PET/ TC excluyen el esqueleto apendicular distal, excepto en casos en los que se considera alta probabilidad de acrometástasis óseas (cáncer de pulmón), por lo que estas lesiones pueden pasar desapercibidas en algunos casos.

Las acrometástasis se convierten en un reto diagnostico dado lo exótico de la presentación y la variada apariencia histológica dependiendo del tumor primario. Prácticamente en todos los casos se hace necesario el estudio de inmunohistoquímica; inicialmente se confirma la naturaleza epitelial de la lesión con citoqueratinas (AE1AE3, CAM 5, 2, CK5/6, etc.) y luego se realizan estudios más específicos orientados a aclarar la neoplasia primaria (ck7, ck20, ttf-1, cdx2, uroplaquina, gata 3 , etc. $)^{(13)}$.

El diagnóstico temprano de las acrometástasis es importante para lograr una adecuada estadificación e iniciar tempranamente diferentes estrategias de tratamiento: fijación quirúrgica, radioterapia y terapia con bifosfonato; con el fin de reducir el riesgo de complicaciones y mejorar la calidad de vida de los pacientes) ${ }^{(6)}$. No existe un protocolo único de tratamiento, por tanto cada caso debe individualizarse)(1). La indicación de la resección quirúrgica es el control del dolor, la cual se hace por medio de resección amplia, curetaje, cementado o incluso amputación ${ }^{(3,8)}$. La tasa de recurrencia local después de curetaje es cercana al 20\%)(1).

Las acrometástasis son reflejo de la diseminación sistémica de la neoplasia, lo que hace necesario un manejo igualmente sistémico con quimioterapia, según el origen del tumor primario. La radioterapia, a pesar de ser muy efectiva para el control del dolor) $)^{(1)}$ está limitada por el número de metástasis, haciendo muy difícil en la práctica tratarlas todas sin generar en el paciente supresión de la médula ósea)(1). Por último, los antirresortivos como los bifosfonatos y el 
denosumab evitan la aparición de nuevas metástasis óseas y disminuyen la frecuencia de eventos óseos adversos que incluyen hipercalcemia, fracturas patológicas, compresión neurológica y dolor óseo, sin embargo, no han demostrado mejorar la sobrevida) $)^{(11)}$.

\section{Referencias}

1. Stomeo D, Tulli A, Ziranu A, Perisano C, De Santis V, Maccauro G. Acrometastasis: a literature review (Internet) (cited 2018 Sep 26). Available from: https://www. europeanreview.org/wp/wp-content/uploads/2906-2915. pdf

2. Maheshwari AV, Chiappetta G, Kugler CD, David Pitcher Jr J, Thomas Temple H. Metastatic Skeletal Disease of the Foot: Case Reports and Literature Review (cited 2018 sep 26); Available from: www.google.com

3. Afshar A, Farhadnia P, Khalkhali H. Metastases to the hand and wrist: An analysis of 221 cases. J Hand Surg Am (Internet) 2014; 39(5): 923-932.e17. Available from: http://dx.doi.org/10.1016/j.jhsa.2014.01.016

4. Muñoz-Mahamud E, Combalia A, Carreño A, Arandes $\mathrm{JM}$. Five cases of acrometastasis to the hand from a carcinoma and review of the literature. Hand Surg Rehabil (Internet). 2017; 36(1): 12-1 6. Available from: http://dx.doi.org/10.1016/j.hansur.2016.10.211

5. Chiu CF, Hsieh CY, Bai LY, Lo WC, Huang HH. Esophageal squamous cell carcinoma with a solitary phalangeal metastasis. South Med J. 2008; 101(11):1 159-160.

6. Sullivan GJO, Carty FL, Cronin CG, Sullivan GJO, Carty FL, Cronin CG. World Journal of Radiology () 2015. 2015; 7(8): 202-212.

7. Nagano $A$, Ohno $T$, Oshima $K$, Ishimaru $D$, Nishimoto Y, Ohno Y, Hirakawa A, Miyazaki T, Akiyama H. Me- tastatic prostate cancer of hand. Case Rep Orthop (Internet). 2016 (cited 2018 sep 26); Available from: https://www.ncbi.nlm.nih.gov/pmc/articles/PMC5097801/ pdf/CRIOR2016-1472932.pdf

8. Flynn C, Danjoux C, Wong J, Christakis M, Rubenstein $\mathrm{J}$, Yee A, et al. Two cases of acrometastasis to the hands and review of the literature (Internet). Vol. 15, CURRENT ONCOLOGY. 2008 (cited 2018 sep 26). Available from: https://www.ncbi.nlm.nih.gov/pmc/ articles/PMC2582515/pdf/co15-5-227e51.pdf

9. Agha K, Akbari K, Abbas SH, Middleton S, McGrath $D$. Acrometastasis following colorectal cancer: A case report and review of literature. Int J Surg Case Rep (Internet). 2016; 29: 158-161. Available from: http:// dx.doi.org/10.1016/j.ijscr.2016.10.078

10. Kim S, Seo K, Song HT, Suh IS, Yoon CS, Ryu JA, et al. Determination of optimal imaging mode for ultrasonographic detection of subdermal contraceptive rods: Comparison of spatial compound, conventional, and tissue harmonic imaging methods. Korean J Radiol. 2012; 13(5): 602-609.

11. Adjei I, Temples M, Brown S, Sharma B, Adjei IM, Temples MN, et al. Targeted Nanomedicine to Treat Bone Metastasis. Pharmaceutics (Internet). 2018 oct 25 (cited 2018 nov 4);10(4): 205. Available from: http:// www.mdpi.com/1999-4923/10/4/205

12. Celià-Terrassa $T$, Kang Y. Distinctive properties of metastasis-initiating cells. Genes Dev. 2016; 30(8): 892-908.

13. Conner JR, Hornick JL. Metastatic Carcinoma of Unknown Primary. Adv Anat Pathol [Internet]. 2015; 22(3): 149-167. Available from: http://content.wkhealth. com/linkback/openurl?sid=WKPTLP:landingpage\& an $=00125480-201505000-00001$ 